\title{
Compreender e ultrapassar as dificuldades de avaliação académica da qualidade da televisão
}

Eduardo Cintra Torres Universidade Católica Portuguesa (UCP) - Portugal - eduardocintratorres@gmail.com Professor e pesquisador do Centro de Estudos de Comunicação e Cultura, da Universidade Católica Portuguesa.

\begin{abstract}
Resumo
As dificuldades de análise da qualidade na televisão são inegáveis: a televisão é uma indústria cultural com uma produção gigantesca, um carácter nacional forte, diferentes formatos institucionais (serviço público, tipos de difusão, cabo, satélite, internet) e uma vocação para gerar todo o tipo de conteúdos. A maioria dos membros do mundo universitário que gravitam em torno dos estudos culturais, mediáticos e de televisão esquivaram-se ou até recusaram-se a dedicar-se a esse exercício de avaliação, o que está longe de estar em conformidade com a concepção segundo a qual o mundo da investigação foi investido pela sociedade desde há dois milénios para avaliar criações culturais nos outros domínios do conhecimento. Neste texto, tento analisar várias causas desta dificuldade ou recusa de avaliação pelos universitários: a instabilidade conceptual de uma "televisão de qualidade"; os domínios de predilecção (programação, escolhas das audiências) ou evitadas (análise textual); a "impossibilidade" de tratar teoricamente a questão da qualidade em televisão; as atitudes neopopulistas ou conservadoras a respeito dos conteúdos.
\end{abstract}

\section{Palavras-chave}

Televisão, qualidade, telejornalismo, TV e universidade. 


\begin{abstract}
The difficulties of evaluating TV quality are undeniable: TV is a cultural industry with a gigantic output, strong national character, different institutional formats (public service, broadcast, cable, satellite, internet) and an omniparous vocation in creating all kind of contents. Academic studies dealing with the evaluation of the media have accepted the more or less loose standards that TV professionals, companies and audiences have used or produced to that end or concentrated the efforts of evaluation in analyzing quantitatively programming slots and genres and in the adequacy of programming to the political normative adapted in each country. Academic attention has partially shifted to the "American quality series", but shared standards of evaluation have not been created. Most academic output has eluded or even refused the evaluation of TV quality by those who have been capacitated by society in the last two millennia to evaluated cultural products and the creations of other areas of knowledge: the academicians themselves. In this paper, I discuss several reasons for the difficulties and the refusal of evaluation by academics: the conceptual instability of "TV quality"; the areas that are either dealt (programming, audiences choices) or avoided (textual analysis); the "impossibility" of dealing theoretically the issue of TV quality; conservative and neopopulist attitudes towards TV contents; ways out of the black hole of academic evaluation of TV quality, with the purpose of helping the development of international work in this area.
\end{abstract}

\title{
Keywords
}

Television, quality, telejournalism, TV and university. 
Estudos em Jornalismo e Mídia - Vol. 10 №2 - Julho a Dezembro de 2013

odos nós que escrevemos sobre televisão temos uma tendência para colocar a
palavra qualidade entre aspas. No meu trabalho de crítica de televisão na
imprensa portuguesa, há 16 anos, ainda antes de reflectir sobre a questão - o que é a qualidade em televisão? - preferi evitar o termo. Em Portugal, nos anos 1990, toda a gente utilizava esta palavra para falar dos programas de que gostava; alguns utilizavam-na como uma inviabilidade da televisão pública, enquanto as leis e os documentos faziam-lhe referência sem a definir. De facto, o discurso público não especializado presume que a qualidade é um conceito partilhado por todos, enquanto evitava de o discutir ou mesmo definir. O conceito de qualidade apresenta-se como uma evidência, mas para mim a evidência é uma alucinação. Como escreveu o filósofo Fernando Gil, a evidência não é evidente. As reflexões universitárias sobre a qualidade resultam dessa assunção da evidência dominante no espaço público, mas enfrentam várias dificuldades.

Como crítico, o que fiz nos primeiros anos foi evitar o termo. Tinha o mesmo problema com o qual sou hoje confrontado no domínio dos estudos de televisão: o que é uma avaliação da qualidade de todo um sistema de televisão ou de uma grelha de todos os programas de um canal sem se ver esses programas? Como avaliar programas populares bem-feitos? E como avaliar programas eruditos malfeitos? E como interferem o meu gosto e as minhas inclinações pessoais nas minhas avaliações? E se interferem, é justo?

Resolvi fazer a apreciação crítica de programas tentando deixar de fora da crítica a questão do gosto (do meu gosto), para me impedir de ser eticamente incorrecto ${ }^{1}$. Por outro lado, ao omitir o termo "qualidade", sugeria que caberia ao leitor decidir se, com base no que escrevia, o programa tinha ou não qualidade. Em 2000, abordei pela primeira vez a questão numa crítica de imprensa intitulada "As elites e os "programas de qualidade"” (Torres, 2000). Utilizei as aspas na expressão "programas de qualidade",

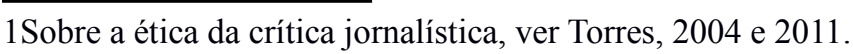


Estudos em Jornalismo e Mídia - Vol. 10 №2 - Julho a Dezembro de 2013

ISSNe 1984-6924

DOI: http://dx.doi.org//0.5007/I984-6924.20I3v10n2p282

atribuindo-a, para me defender, às elites. No artigo, lamentava o uso dos conceitos de qualidade nos termos acima referidos, adiantando:

Para se definir a qualidade dum programa é preciso afastarmo-nos de padrões dum grupo ou classe e, em vez disso, tomar em conta o seu conteúdo, a sua narrativa, as formas técnicas de representação da realidade, os conceitos ideológicos subjacentes, e o acordo de conteúdo e formas aos públicos alvos desse programa. Precisamos de saber se os níveis técnicos, de representação e ideológicos se interpenetram e "fazem sentido", numa acepção profunda. Só assim poderemos aplicar o conceito de qualidade enquanto característica neutra.

No mesmo artigo, lamentava que a concepção de qualidade continuasse "envolta em pantanosa confusão. A questão dos 'programas de qualidade ocorre sempre nos artigos mais abstractos sobre TV, em especial sobre serviço público como algo vago, nunca concretizado". Continuo a pensar como em 2000, apesar de a qualidade da televisão em geral (se é que essa categoria tão geral faz sentido) ser uma questão mais complexa do que a dos programas. A complexidade, a variedade das abordagens e o conteúdo do próprio termo "qualidade" foram sistematizados por Eva Pujadas em La televisión de calidad - Contenidos y debates (2011). Abstenho-me de, aqui, reproduzir todas as abordagens - políticas, profissionais, criativas, de recepção e académicas, nacionais e internacionais - que a autora esgotou no seu livro, que considero um guia fundamental para todos os que queiram começar investigações sobre a qualidade em televisão.

Contrariamente ao que muitos pensavam, eu incluído, o universo académico produziu um número razoável de trabalhos sobre este tema. Mesmo se, nos anos 1980, o conceito de qualidade foi "posto no índex" (Schroeder, 1997: 109), o interesse pela qualidade da televisão desenvolve-se nos anos 1990, não apenas devido ao novo prazer estético dos investigadores com as séries americanas, mas também por aquilo o que David Bernard define como uma verdadeira obsessão contemporânea pela qualidade, transformada em ideologia da qualidade (Bernard, 2008). Talvez também nós estejamos incluídos; será decerto necessário prudência para evitarmos os efeitos nefastos que Bernard analisou no campo das estruturas de emprego em França. De qualquer modo, 
Estudos em Jornalismo e Mídia - Vol. 10 №2 - Julho a Dezembro de 2013

ISSNe 1984-6924

DOI: http://dx.doi.org//0.5007//984-6924.2013v10n2p282

desde há cerca de cinco décadas, encontramos artigos e investigações sobre a qualidade, em Inglaterra, Canadá, Estados Unidos, França, Japão, Escandinávia e, nos últimos anos, na Argentina e noutros países da América Latina, além de Portugal e Espanha. Em Portugal, em 2009 e 2010, procurámos realizar uma investigação multidisciplinar e internacional, que infelizmente não foi para a frente, por falta de apoio financeiro da entidade que tem a seu cargo as subvenções à investigação cientifica nesta área. Um dos objectivos da investigação era precisamente o de procedermos a um recenseamento bibliográfico internacional sobre a qualidade na televisão.

Quando se percorre a literatura publicada sobre o assunto, uma constatação marcante é a de que, contrariamente a outros campos do conhecimento, há uma dispersão, seja de carácter nacional, seja no modo de abordar o tema. Desde que ele entrou nos manuais de estudo da televisão, não criámos um paradigma ou paradigmas sucessivos que fossem incorporados na literatura das ciências da comunicação e, porque não, na literatura normativa e legal dos serviços públicos de televisão. Não há, porém, que ficar espantado, pois ainda não fomos capazes de definir o que é a qualidade, tendo mesmo generalizado o uso da palavra entre aspas: "a eterna questão da 'qualidade' e de como ela deve ser definida ou reconhecida" (McQuail, 2010: 114). As aspas recebem mesmo o nome de "as aspas do medo" (Caughie, 2000: 23). No livro do Observatório Íbero-Americano da ficção televisiva, de 2011, consagrado precisamente à "qualidade da ficção televisiva", encontramos essa e outras expressões entre aspas, como "padrão Globo de qualidade", "ficção americana de qualidade" etc. (Obitel, 2011).

O uso das aspas "do medo" significa que não estamos ainda em condições nem de legitimar o conceito num contexto de avaliação da televisão nem de reconhecer a própria autoridade de uma avaliação académica do tema. Significa ainda que a palavra é usada como um travão e que não se sabe ao certo o que quer dizer. Acontece de o mesmo autor usar o termo qualidade entre aspas, mas não as colocar numa derivação dela, como é o conceito de tele-lixo (Pujadas, 2011). Em consequência, a minha primeira nota de reflexão consiste em constatar a instabilidade da terminologia e conceptual entre os universitários. Eis um conceito do qual se deve falar - e falamos bastante - com aspas, mesmo sem o definirmos ou dizendo que não o podemos definir. As dificuldades em torno deste tema criam um atavismo colectivo que está na origem de 
Estudos em Jornalismo e Mídia - Vol. 10 №2 - Julho a Dezembro de 2013

ISSNe 1984-6924

DOI: http://dx.doi.org//0.5007//984-6924.2013v10n2p282

um fenómeno de ex-denominação ou de ocultação. Sem paradigmas sobre os quais nos apoiarmos, falamos do que não chegámos a sistematizar, ou usamos uma concepção privada, pessoal, de qualidade - a minha, a do meu grupo de investigação, da minha universidade, do meu país.

Devido a esta instabilidade, os conceitos podem mesmo tornar-se quase esotéricos, como as diferenças que Sarah Cardwell procura entre "televisão de qualidade" e "boa televisão", o que a leva a criar as subcategorias de "televisão de "má' qualidade" e de "boa televisão sem qualidade" (Cardwell, 2007). Com o mesmo tipo de artifícios retóricos, pode também transformar-se o substantivo em adjectivo e vice-versa na distinção entre "a qualidade da ficção" e "a ficção de qualidade" (Buonnano, 2004). E poderíamos encontrar um traço da instabilidade terminológica se o título deste colóquio tivesse, depois da pergunta - e é uma interrogação - "O que é uma televisão de qualidade?”, a questão invertida: “O que é a qualidade da televisão?” Nos dois casos, perguntamos (além disso, o nosso título propõe uma televisão de qualidade e não $a$ televisão de qualidade). As palavras, sempre o nosso grande problema!

A minha segunda nota de reflexão diz respeito aos temas abordados nos trabalhos sobre a qualidade em televisão. Por outras palavras: que domínios da televisão se quer abordar? Dado que Eva Pujadas já sistematizou esta questão, permitome segui-la (2011:83). Os temas são quatro: qualidade do sistema, da programação, dos canais e dos programas. ${ }^{2}$ É todo um programa, e bem original, se comparado com as outras áreas culturais. Os trabalhos mais antigos concentram-se nas questões institucionais; dado que se vivia na Europa a idade de ouro da televisão broadcast e dos monopólios dos Estados, a principal preocupação dizia respeito à adequação dos canais e sistemas de televisão aos princípios políticos e institucionais. Além disso, um canal de televisão era considerado (e ainda hoje acontece) como uma unidade e um fluxo, o que fazia derivar a apreciação da qualidade a critérios globalmente políticos e institucionais, dando destaque a ideias relativas à diversidade dos géneros apresentados em antena. $\mathrm{O}$

2 Em 1990, Alain Le Diberber, então conselheiro técnico do ministro francês da Cultura e da Comunicação, enumerou três tipos de qualidade da televisão: do programa, do sistema e do serviço, este incorporando aspectos da programação e dos canais (Le Diberber, 1990). Estas tipologias assemelham-se às que Lasagni e Richeri propuseram em 1996: qualidade do programa, dos géneros, do canal e do sistema (1996). 
Estudos em Jornalismo e Mídia - Vol. 10 №2 - Julho a Dezembro de 2013

ISSNe 1984-6924

DOI: http://dx.doi.org//0.5007/I984-6924.20I3v10n2p282

objectivo da investigação consistia em verificar a relação entre a diversidade legalmente instituída, isto é, o que o canal deveria apresentar, e o que efectivamente difundia. A diversidade era essencial e constitui ainda hoje uma das variáveis que os investigadores, tal como os políticos, se empenham em controlar (por ex., Ishikawa, 1996; Borges, 2009; Borges e Reia-Baptista, 2008). Essa avaliação da diversidade, que em alguns casos é hegemónica, abstém-se da avaliação dos conteúdos, o que é uma característica original de diversas investigações.

É, todavia, necessário constatar que também existiu um interesse pela qualidade dos conteúdos, questão à qual voltarei. Gostaria aqui de sublinhar que, nos últimos anos, o desenvolvimento desse interesse decorreu sobretudo da percepção da qualidade da ficção norte-americana pelos investigadores. Pode dizer-se que o debate se afastou para a qualidade da ficção televisiva. Verifica-se, assim, de novo, um fenómeno de exclusão. Os trabalhos anglo-americanos que abordam a questão da qualidade concentram-se nas séries de ficção, em detrimento da informação, dos documentários e do entretenimento. $\mathrm{Na}$ Grã-Bretanha, publicaram-se investigações sobre a "ficção americana de qualidade", como a obra colectiva Quality popular television (Jancovich e Lyons, 2003), que trata exclusivamente dessa "nova categoria de televisão de 'culto', produzida principalmente nos Estados Unidos". Outra obra colectiva de grande interesse, editada por McCabe e Akass (Quality TV, 2007), promete, desde o subtítulo, tratar da "televisão norteamericana contemporânea e mais para além”. O livro resulta de uma conferência internacional realizada na Irlanda sob o título: "Conferência sobre a qualidade da televisão americana". Em 2005, saiu The Contemporary Television Series, obra que a editora apresenta como "um excitante e provocador estudo sobre o formato serial de 'qualidade' no prime-time televisivo contemporâneo" (Hammond e Mazdon, 2005). É verdade que, enquanto novo campo de investigação, as séries merecem a nossa atenção; Jean-Pierre Esquenazi lamenta a falta de interesse na França pelas proezas americanas nesta área e a pequena quantidade de séries europeias que se lhes possam comparar (Esquenazi, 2011). Identificamos aqui, todavia, outro atavismo, o da exclusão da maioria da produção do campo de observação por parte dos investigadores. Parece que o mesmo fenómeno se passa com o cinema. Laurent Jullier (2002), em Qu'est-ce q'nu bon film? (e notemos a interrogação), exclui da sua análise os documentários e outros 
Estudos em Jornalismo e Mídia - Vol. 10 №2 - Julho a Dezembro de 2013

ISSNe 1984-6924

DOI: http://dx.doi.org//0.5007//984-6924.2013v10n2p282

formatos fílmicos contemporâneos, concentrando-se apenas no cinema de fiçcão. $O$ novo e tendencialmente exclusivo interesse académico pela ficção decorre sobretudo do desenvolvimento pela indústria americana de séries de grande investimento e grande cuidado formal e narrativo. Há quinze anos, um dos investigadores que consagrou mais atenção à qualidade escrevia ainda que os aspectos "técnicos" eram de menor importância na avaliação (Raboy, 1996:68). Desde então, isso mudou muito, sendo hoje um dado adquirido que a qualidade da ficção decorre também de características técnicas, quer dizer, formais.

A atenção dos investigadores começou por voltar-se para a ficção americana com séries como Hill Street Bules, Twin Peaks e E.R. Robert Thompson chamou a este período de 1981-91 a "primeira idade de ouro da televisão" ou da "televisão de qualidade" [entre aspas] nas networks americanas" (Thompson, 2007: xvii). Ocorreu uma evolução similar na Grã-Bretanha, com séries como Jewel in the Crown, Brideshead Revisited e as séries de Dennis Potter, como The Singing Detective. A "segunda idade de ouro" chega com o advento do nosso século e títulos como The Sopranos, Six Feet Under, The Simpsons, The Wire e Mad Men. Esta segunda fase é mais independente relativamente à televisão generalista, sendo várias séries apresentadas em canais de televisão paga, como a HBO. O famoso slogan da $\mathrm{HBO}-$ It's not TV, ti's $H B O$ - subentende um conceito de qualidade diferente do da televisão generalista e, em consequência, plebiscita uma nova idade do media (Leverett, Ott e Buckley, 2008).

Deve reconhecer-se que depois do primeiro período do estudo da qualidade do media, ao qual se pode chamar o "período do serviço público", o tema da televisão de qualidade voltou à ordem do dia em parte por causa das preferências e do gosto dos investigadores por certos programas de ficção. $\mathrm{O}$ segundo período - a que chamarei "período da ficção norte-americana" - deixou fora de campo conteúdos como a informação, o entretenimento e outros géneros, como é bem visível nos relatórios nacionais do Obitel de 2011. Esta camisa de forças reduz o conceito e o debate a um único domínio (a ficção, e em particular uma certa ficção que retém a atenção dos investigadores). Por conseguinte, torna-se difícil abordar a questão da qualidade dos conteúdos em toda a sua plenitude. A análise preferencial de um só tipo de programação 
Estudos em Jornalismo e Mídia - Vol. 10 №2 - Julho a Dezembro de 2013

ISSNe 1984-6924

DOI: http://dx.doi.org//0.5007/I984-6924.2013v10n2p282

não permite construir um ou vários modelos de avaliação para todos os textos $\mathrm{e}$ conteúdos televisivos segundo critérios semelhantes ou em sintonia entre todos. Além disso, tratar da qualidade a partir de um só género torna mais difícil debater a qualidade na televisão em termos teóricos, e, portanto, generalizáveis e universalmente válidos se tal tarefa é possível. E isso só se poderá saber tentando-se.

Chegamos assim a uma terceira nota de reflexão: vários textos evocam a provável eventual impossibilidade de tratar teoricamente a questão da qualidade dos conteúdos. A principal razão seria a de que a avaliação enfermaria uma dimensão de subjectividade impedindo qualquer consenso no próprio seio da comunidade cientifica. Autores nórdicos dizem-no claramente: é mais natural pensar a qualidade ou excelência "como qualquer coisa atribuída a uma coisa ou a uma pessoa dotadas de certas características, resultando a atribuição principalmente de se as considerar aceitáveis à luz de um conjunto de valores e de normas mais ou menos básicas. Uma característica é, pois, qualquer coisa que se possui, enquanto a excelência é atribuída" (Rosengren et al, 1996: 5). O facto de a qualidade ser atribuída significa para estes autores, mas também para diversos outros, que outros agentes devam estar implicados no processo de avaliação: o mundo político, os profissionais do media e os públicos.

Na minha opinião, esta impossibilidade de avaliarmos nós mesmos a qualidade da televisão é uma posição próxima do idealismo filosớico, mas impôs-se neste aspecto aos investigadores, o que não é o caso nos outros domínios do saber e do conhecimento. Com efeito, o universo cientifico realiza constantemente avaliações igualmente subjectivas, atribuindo-lhes, aliás, um carácter tão objectivo que pode mesmo tornar-se quantitativo. Pode dizer-se que a quantificação da qualidade, enquanto sinónimo de avaliação, é um dos processos fundamentais da actividade cientffica dos professores. Quando um professor dá notas aos seus alunos, transforma em números uma avaliação amiúde baseada em avaliações subjectivas dos seus trabalhos, testes, exames, etc. As revistas cientificas avaliam os nossos artigos e são elas mesmas avaliadas, tal como as próprias universidades. Exagero um pouco, é certo, na comparação. Mas, olhando para a literatura e as belas artes, a construção dos cânones é igualmente uma tarefa na qual os cientistas e especialistas trabalham sem cessar e sem tomar em conta agentes exteriores ao seu meio. No entanto, haverá investigadores que pensem em avaliar do mesmo modo 
Estudos em Jornalismo e Mídia - Vol. 10 №2 - Julho a Dezembro de 2013

ISSNe 1984-6924

DOI: http://dx.doi.org//0.5007/I984-6924.20I3v10n2p282

e mesmo em quantificar a qualidade da televisão? Fizeram-no alguns nos países do Norte da Europa e no Canadá desde há alguns anos, tal como colegas da Universidad Austral, de Buenos Aires. Mas a maioria de nós prefere analisar a avaliação sem dar o passo seguinte.

Tal é tanto mais estranho quanto a avaliação e a quantificação da qualidade são muito comuns na sociedade. Precisamos dela por razões práticas e de orientação mútua. Por vezes, usamos critérios simples para avaliações facilmente quantificáveis, por vezes usamos critérios complexos, diversificados e demorados. Por exemplo, avaliar a qualidade da água é simples, se os critérios forem os da quantidade de cloro ou de impurezas. Avaliar a qualidade de uma empresa já é uma actividade mais complexa, mas feita correntemente e obrigatória em certas actividades: a certificação da qualidade tornou-se, pelo menos na União Europeia, uma actividade por si mesma. Nos media, os políticos são avaliados com escalas numéricas. Os países são sempre classificados por agências de rating através de uma notação numérica. Não faltam exemplos.

As actividades culturais são diferentes pela sua natureza das que acabo de referir, mas não escapam por isso à avaliação. A classificação de obras artísticas começou na Antiguidade: a lista das Sete Maravilhas do Mundo foi realizada pela primeira vez por intelectuais do século II a.C., um escritor e um matemático. Ainda hoje retém a sua aura. Há décadas que os críticos dos media, recorrendo ao truque das estrelinhas, avaliam quantitativamente livros, ensaios, romances, poesia, filmes e espectáculos. Quase todos os géneros são submetidos a avaliação quantitativa. Muitos destes críticos têm formação cientffica ou são mesmo universitários.

Em resumo, enquanto se realiza quantitativa e/ou qualitativamente a avaliação da qualidade em várias actividades económicas, políticas, sociais, cientificas e culturais, nós temos tido historicamente não só dificuldades sérias de avaliar os conteúdos e a própria televisão, mas, antes mesmo, de nos pôr de acordo sobre o modo de o fazer e sobre a bondade de tal iniciativa. Apesar das tentativas corajosas que mencionei, não dispomos de um ou mais paradigmas partilhados, debatidos e aplicados pelos estudos sobre a televisão.

Uma razão para esta dificuldade está na origem da minha quarta nota de reflexão: a existência de certa atitude de demissão no mundo académico em realizar 
Estudos em Jornalismo e Mídia - Vol. 10 №2 - Julho a Dezembro de 2013

ISSNe 1984-6924

DOI: http://dx.doi.org//0.5007//984-6924.2013v10n2p282

essa tarefa. Essa atitude traduz-se de diversas formas e pode atingir casos incompreensíveis, como é o caso, a meu ver, do livro de Gillian Rose Visual Metodologias. Dedicado às teorias e práticas das metodologias visuais, o livro não dedica uma só linha à análise de imagens televisivas. Mais ainda, o único capítulo em que se fala de televisão é dedicado às audiências: "Estudos de audiência: estudando como a televisão é vista" (Rose, 2008: 196). A autora transfere para a audiência o poder único de análise do texto visual da televisão e considera o modo como a audiência vê televisão como uma "metodologia visual". Em 1996, um autor colocava em quarto lugar o papel do investigador da qualidade em televisão, mas resumia-o à análise da recepção, como intermediário que ajuda a produção de emissões mais adaptadas aos espectadores, sem comprometer nem a criatividade do comunicador nem a qualidade dos programas (D’Haenens, 1996). Além disso, exagera-se as dificuldades do próprio processo de avaliação. Considera-se irrealizável ou nefasto estabelecer critérios comuns, nomeadamente para a avaliação de géneros e de programas. Jane Feuer interroga-se sobre as diferentes atitudes em relação à ficção da $\mathrm{HBO}$ e a reality $T V$ : "Dado que a TV de realidade, de modo discutível, nem mais nem menos 'original' que o drama da HBO e dado que ambos os géneros têm os seus autores e os seus génios, porque deveria uma das formas ter tão mais estatuto artístico do que o outro?" (Feuer, 2007: 156; notemos, de novo, a interrogação e as aspas). Apercebemo-nos que há uma verdadeira desistência dos académicos quando se trata da avaliação. Ela compete, dizem-nos, ao mercado, ou pelo menos o mercado deve comparticipar nessa avaliação, dado tratar-se de uma actividade industrial. Aplicando o mesmo critério, poderia pensar-se da avaliação de um livro ou de uma editora a partir da posição do editor, ou de uma fábrica a partir da posição do industrial, e não a partir dos produtos, por exemplo. Pensando bem, é muito bizarro que alguém se avalie a si mesmo numa avaliação que se quer independente. Naturalmente, a opinião dos profissionais de televisão é importante, porque neste media a obra é sempre colectiva e tem uma cadeia económica complexa, mas não para a avaliação independente do que produzem, isto é, os conteúdos que põem à disposição do público.

No que diz respeito à consideração da avaliação pelos públicos, muito defendida desde os anos de 1970-80 pelos Cultural Studies, trata-se de um tema complexo. 
Estudos em Jornalismo e Mídia - Vol. 10 №2 - Julho a Dezembro de 2013

ISSNe 1984-6924

DOI: http://dx.doi.org//0.5007//984-6924.2013v10n2p282

Sabemos actualmente infinitamente mais sobre as audiências do que há poucas décadas. As investigações sobre as audiências, são, aliás, uma das grandes conquistas dos estudos sobre televisão, talvez mesmo a sua maior glória. Mas, como sabemos, começaram precisamente como alternativa dos Cultural Studies à avaliação cientf̂́ica dos conteúdos, como uma alternativa à demissão de avaliar.

Na década de 1990, o investigador dinamarquês Kim Schrøeder defendeu uma concepção teórica a partir das "leituras feitas pelos públicos" de emissões concretas, "em função dos seus gostos" (Schrøeder, 1997: 110). Baseava-se em especial em autores americanos, para quem a "noção de qualidade está estreitamente ligada à experiência do público" (idem: 111), e que partem duma concepção do público como parte integrante do mercado. ${ }^{3}$ Um dos autores citados, Michael Schudson, propunha que se verificasse se "a qualidade de uma arte depende da maneira como é recebida, ou, mais exactamente, da maneira como é criada num contexto da recepção. Não se trataria, portanto, de uma qualidade intrínseca ao objecto artístico" (apud, idem: 114). O modelo de análise de Schrøeder, baseado sobre a ideia de que "todo o juízo sobre a qualidade deveria depender daquilo que o público possa dele extrair", contradiz-se na sua própria formulação, porque propõe a seguir, a propósito das leituras de um texto por um público, que se interrogue se as suas leituras "manifestam [...] uma dimensão ética [...] uma dimensão estética [e] uma dimensão extática” (idem: 119). Para encontrar respostas, Schrøeder cria as suas variáveis, e não as do público, e aplica-as, como tantos outros investigadores - e sem nenhuma explicação - a um exemplo recolhido na ficção televisiva. Todavia, o modelo deveria aplicar-se antes a estudos de audiência e não como uma negação da avaliação pelo mundo universitário. Schrøeder considera que não se pode "tomar a temperatura constantemente" à qualidade e, citando J. Mephan, afirma que "não existe uma aritmética da qualidade (idem). Remetendo-se assim a avaliação para as mãos da audiência (mesmo se segundo os nossos critérios), a iniciativa não pertence aos universitários. Em consequência, um dos critérios de avaliação é, inelutavelmente, o êxito junto das audiências, quer dizer, "na prática, o critério do

3 Podemos interrogar-nos se uma parte da audiência não se vê a si mesma como parte do mercado. De qualquer forma, a avaliação pelo público pode ter manifestações independentes da investigação universitária. Por exemplo, a que é feita pela associação americana Viewers for Quality Television (Swanson, 2000) e muitas outras, noutros países, como em Portugal. 
Estudos em Jornalismo e Mídia - Vol. 10 N² - Julho a Dezembro de 2013

ISSNe 1984-6924

DOI: http://dx.doi.org//0.5007//984-6924.2013v10n2p282

sucesso precede qualquer noção de qualidade intrínseca" (McQuail, 2010: 118). Neste caso, se o mundo cientifico aceita o êxito junto das audiências como um critério de qualidade válido em substituição de critérios que lhe sejam próprios, aceita-se o critério do mercado ao dar ao público o que ele quer, rejeitando a crítica que Aristóteles dirige aos poetas que "seguem o público e se acomodam ao seu gosto" (Aristóteles, 2000: 1453a, 35). Acresce que a aceitação da audimetria dos programas de televisão, enquanto reflexo de preferências baseadas em noções de qualidade partilhadas pelo espectador, é abusiva.

A colocação da avaliação nas mãos da audiência impôs-se quando o governo britânico conservador de Margaret Thatcher empregou o termo de qualidade, de um ponto de vista do mercado, no seu programa A Televisão para os Anos 90 (Schrøeder, 1997: 110). Para o contrariar, os universitários recorreram aos estudos culturais de modo a "reabilitar o povo". Schrøeder considera que os investigadores "progressistas" antiThatcher evitaram a avaliação da qualidade dos programas concretos centrando a discussão na "qualidade da programação em geral" e criando o conceito de diversidade (idem: 109). ${ }^{4}$ Esta demissão ideológica traduz um "populismo cultural" (McGuigan, 1997, 2010) ou um "neo-populismo" que se desenvolveu "principalmente no mundo universitário anglo-saxónico desde os anos 80" (Bourbon, 2009: 82). Schrøeder antecipa a crítica: "consideremos a possibilidade de os meus critérios serem populistas" (1997: 122). O populismo cultural apresenta-se como contraponto à posição elitista, supostamente arrogante e autoritária, de estabelecer padrões de qualidade de cima para baixo, para toda a população. O histórico dos canais comerciais, bem como a riqueza da oferta audiovisual, incitavam à celebração de uma (relativa) autonomia das escolhas populares em nome de um "poder semiótico" (Fiske, 1987: 126). Apesar de o "neopopulismo" se inscrever agora numa corrente marxista glorificando a autonomia do consumidor (McGuigan, 2010), tornava-se um projecto, segundo Todd Gitlin, dedicado

4 Pode considerar-se, com Jullier, a propósito do relativismo cultural de esquerda segundo o qual tudo se equivale, que, "no fundo", ela considera que o público popular é "incapaz de apreciar a obra-prima" (2002: 240). Com efeito, os "demissionistas" da análise de qualidade fazem uma operação política: recusando que se possa avaliar a qualidade de programas segundo critérios verificáveis e partilhados - e tão aceitáveis como critérios de produção e de recepção - autores como Schrøeder cometem a omissão para validar os conteúdos ditos populares com as mesmas ferramentas hegemónicas que condenam na avaliação pelos critérios da cultura dita erudita. 
Estudos em Jornalismo e Mídia - Vol. 10 N² - Julho a Dezembro de 2013

ISSNe 1984-6924

DOI: http://dx.doi.org//0.5007/I984-6924.20I3v10n2p282

a inverter a velha hierarquia dos valores culturais sem todavia a abater, de tal modo que acabava mesmo por ser um "eco da lógica do capitalismo" sem lhe opor (Gitlin, 1997: $32)$.

Considero que entregar a avaliação às audiências é, em si mesmo, e ao mesmo tempo, um acto de não-avaliação e um acto de avaliação. Por um lado, é uma nãoavaliação porque o académico a entrega a outrem. Por outro, é uma avaliação porque não avaliar é em si mesmo legitimar essa avaliação de outrem e porque o académico assume como conveniente ou suficiente a avaliação pelas audiências. Além disso, o académico coloca-se na estranha posição de se excluir do universo dos públicos de televisão.

Os estudos de audiência são, em primeiro lugar, investigações sociológicas, mas o facto de a televisão ser uma magic box que diz respeito a todos os domínios da vida em sociedade levou os investigadores a fazerem de certos estudos sociológicos estudos culturais, dando a primazia à recepção em detrimento da obra recebida. Se não ouso afirmar que em certos estudos a obra recebida não existe porque só existe pela recepção, pode dizer-se que os Cultural Studies se desinteressaram do texto.

Do meu ponto de vista, abandonar a análise do texto constitui uma demissão do papel do investigador na sociedade. Além disso, limitar a análise do texto que se vai fazendo à ficção, nomeadamente à ficção americana, deixa todo um universo de produção audiovisual fora do campo de observação duma parte da sociedade - a universidade - que teria, por consenso social, um mandato para o fazer. E o facto de os programas que normalmente ficam de fora da análise estarem precisamente entre os mais apreciados pela audiência - programas que se caracterizam, por vezes, por uma certa pobreza nos domínios artístico, estético, narrativo, temático, etc. — deveria voltar a atenção da investigação para eles. Creio, porém, que os autores neo-populistas que se opõem à avaliação dos programas temam que, fazendo-a, a sua argumentação sobre a avaliação dos programas caia por terra. Em resumo, considero que a posição académica de entregar a avaliação nas mãos de outros agentes é uma demissão do papel do investigador pelo próprio investigador.

Outro embaraço da avaliação académica da qualidade diz respeito à recusa parcial, ou mesmo total, de analisar concretamente um dado programa de televisão. Esta 
Estudos em Jornalismo e Mídia - Vol. 10 №2 - Julho a Dezembro de 2013

ISSNe 1984-6924

DOI: http://dx.doi.org//0.5007/I984-6924.20I3v10n2p282

postura decorre, em parte, por se considerar a televisão e os canais em bloco, devido ao princípio político de antigamente segundo o qual a diversidade constitui uma obrigação das estações generalistas. Daí resulta uma análise da programação vertical, horizontal ou por blocos de programas, como a que faz a Universidad Austral. Esta atenção sobrevaloriza a capacidade de considerar a qualidade fora dos programas que compõem as grelhas.

Não é meu objectivo subestimar a avaliação da ou das programações. Contudo, no quadro da demissão da avaliação de programas concretos, vejo uma avaliação com menos de especificamente académico do que de político, ajudando o sistema político a verificar a observância das obrigações de serviço público, sobretudo no que diz respeito à diversidade. Os investigadores do estudo da NHK (Ishikawa, 1996: vii-ix) adoptaram a estratégia de analisar a qualidade da difusão e não a qualidade da televisão na oferta concreta de programas. A investigação incluiu a opinião de profissionais e das audiências, mas não a análise de programas. Não conheço estudos da qualidade da diversidade que discutam o próprio conceito de diversidade, imposto pelo sistema político, e as suas componentes, por exemplo, reflectindo sobre o conceito e as práticas de entretenimento nos serviços públicos na era da multiplicação da oferta nesta área. A meu ver, se a verificação da qualidade se fizer (apenas) com base na análise superficial do conjunto da programação (os géneros, os tempos de cada um nas grelhas), desprezase aquilo que com o espectador está verdadeiramente em contacto: os programas concretos. Os espectadores não vêem "programação", vêem, nós vemos este programa, uma parte dum programa, vários programas. Precisando este ponto, nós não vemos televisão do mesmo modo que não lemos uma biblioteca ou que não vemos o cinemavemos um filme ou filmes, lemos um livro ou livros. É nos programas que a programação ganha forma. Sucede o mesmo quanto à qualidade. Em Portugal, foram publicadas diversas análises da qualidade fundadas na programação, o que, a meu ver, produz um resultado nefasto, pois ignoram o que eu realmente vi na televisão. As próprias categorias dos programas, fornecidas pelos canais, não são verificadas, mesmo que os programas concretos tenham sido correctamente catalogados nessas categorias. Acontece um programa de entretenimento ser classificado como documentário. E ninguém verifica. Se um canal observa as quotas quantos aos géneros - a diversidade 
Estudos em Jornalismo e Mídia - Vol. 10 N² - Julho a Dezembro de 2013

—, sem que os programas disponham de quaisquer outras qualidades, a avaliação resultante é enviesada. Assim, parece-me que a análise quantitativa das quotas não deveria renunciar à avaliação concretas das partes que formam o conjunto. Um dos problemas reside no facto de que os políticos não poderiam fazer essa avaliação politicamente incorrecta, enquanto podem fazer a verificação da diversidade. Qual o resultado? "É provável que princípios de qualidade cultural sejam apresentados como desejáveis, mas raramente se fazem valer" (McQuail, 2010: 206). Há um paradoxo no facto de os políticos não fazerem a avaliação da qualidade (programas), mas fazerem uma avaliação de qualidade (diversidade). Mas não discutamos questões de poder.

Voltemos antes à dificuldade de avaliar com base na programação da era da segmentação dos programas e da sua recepção pelo indivíduo empoderado, investido da soberania de ver o que ele ou ela quer, quando ele ou ela quer. O que restou do nosso fluxo? O que será que vai ficar para depois? Uma foto antiga, talvez um quadro sinóptico. O empoderamento, a habilitação do espectador, desmobiliza a grande importância que se possa atribuir à "audimetria da primeira vez", ao fluxo como elemento ontológico da televisão, e acrescenta à singularidade de cada conteúdo. Além disso, o desenvolvimento da televisão temática obriga-nos a pôr em acção critérios alternativos à diversidade, pois não se aplicam. É um novo argumento para reforçar que se investiguem métodos sistemáticos de avaliação de programas concretos.

Eis-nos chegado à quinta nota de reflexão. A meu ver, a análise da qualidade deve aplicar-se a todos os tipos de conteúdos televisivos. Não só às séries americanas e outros programas "ricos", mas também aos programas mais "pobres", a todas as unidades textuais, como os programas do daytime, os telejornais, as reportagens, as telenovelas, os telefilmes, os documentários, a música, os reality shows, os jogos televisivos, a publicidade, as autopromoções etc. Todos os textos são susceptíveis de avaliação da sua ou das suas qualidades. Todos conhecemos análises desse tipo de um ou de outro programa, mas, em geral, mesmo quando se trata de uma análise textual e não sociológica ou da recepção, não se dá o passo para o lado da qualidade.

Penso que é possível encontrar critérios de análise da qualidade para todos os tipos de programas, sejam "ricos" ou "pobres", eruditos ou populares. É necessário que se defina, sem dramas, a qualidade dos programas populares com base no que eles são 
Estudos em Jornalismo e Mídia - Vol. 10 N² - Julho a Dezembro de 2013

ISSNe 1984-6924

DOI: http://dx.doi.org//0.5007/I984-6924.20I3v10n2p282

verdadeiramente, no que dizem e no que mostram, e não apenas com base no critério de juízo dos homens políticos, dos profissionais e das audiências. Trata-se de um trabalho que deve ser primeiramente realizado por aqueles que estudam a televisão. É preciso apoiar-se nas características propriamente ditas do texto e dividir a análise segundo o que podemos chamar, como sugere Laurent Jullier, os "critérios objectivos de coerência, de edíficação "vista como um misto de visibilidade e de complexidade" e de originalidade (2002: 46). Não avaliou Aristóteles a qualidade interna dos textos e dos espectáculos teatrais de Atenas?

A minha sexta nota de reflexão diz respeito à relação entre o texto de televisão e o seu contexto quando se avalia a qualidade. A meu ver, mesmo que a avaliação não deva assentar exclusivamente nos aspectos textuais, estéticos e técnicos, o texto é o único material que nos permite aceder ao que o espectador efectivamente recebe. Para o melhor e para o pior, ele só existe nas suas formas. Victor Hugo dizia: "A forma é o fundo que volta à superfície". Só se pode analisá-las pelo que elas nos dão a ler, a ver e a ouvir. É preciso fazer a economia das palavras, dos sons, das imagens, dos cenários, das paisagens, da apresentação ou das performances dos jornalistas, dos animadores, dos actores ou dos convidados, da iluminação, dos acessórios, da realização, da banda sonora, da montagem etc. E também do argumento, da narrativa, da estrutura, do tema e do tom, a fim de analisar a "coerência" e a "integridade estilística" (Cardwell, 2007: 30) do conjunto ou, por outras palavras, a maneira como o texto "faz sentido". Todos os textos têm de ser confrontados com os critérios de uma ética que lhes seja própria, como a deontologia do jornalismo nos programas de informação, as regras do jogo nos jogos televisivos etc. A meu ver, todas estas características fazem parte da techné da criação televisiva, e é a nós que cabe sistematizar a reflexão sobre essa techné. Alguns meios de avaliação decorrem do contexto (artístico, ético, legal, programação, etc.), mas é sobretudo a conformidade do texto que deve reter a nossa atenção. Por exemplo, a apresentação de um programa para um público adulto num horário infantil é um elemento de contexto que nada tem a ver com o texto em si. Mas se um programa viola, no seu conteúdo, as regras sociais e legais difundindo, por exemplo, afirmações racistas, deve tomar-se em conta as "questões de moral e de decência" quando se trata da "qualidade da prestação cultural” (McQuail, 2010: 167). 
Estudos em Jornalismo e Mídia - Vol. 10 N² - Julho a Dezembro de 2013

A montante, não se pode ignorar os elementos da produção, distribuição e apresentação do canal, o horário, a origem nacional etc., que acrescentam a explicação do texto, mas não devem substituir a análise crítica e académica pela visão dos criadores e do mercado. Por exemplo, acabo de fazer a análise de um seriado televisivo português, A Raia dos Medos, e uma longa entrevista com o argumentista, aliás muito interessante, quase nada acrescentou à análise do texto audiovisual: não o alterou, ajudou a explicálo.

A jusante, os elementos da recepção contribuem para a análise: as medições de audiência, a opinião e o feedback interactivo dos receptores no que aos textos diz respeito. Mas, de novo, é preciso ter em conta que estes elementos não podem substituir a análise crítica e académica pelo juízo da audiência, apenas podem contribuir para a busca de elementos que possam esclarecer a análise do texto. Por exemplo, a análise deve tomar em conta que a maioria dos textos — senão todos — é feita para uma "audiência presumida" (Ellis, 1992: 115) ou um "público presumido" (Sánchez Noriega, 2002: 115), que correspondem ao "leitor pressuposto" da teoria da recepção literária, aquela que o autor tem na cabeça (Silva, 1991: 308): o conjunto dos espectadores presumidos ou pressupostos constitui o público-alvo (target) da indústria audiovisual. É certamente possível perguntar aos criadores e profissionais qual era o alvo dos seus programas, mas não o evidenciaram eles já com competência no texto? Mais vale interrogar o texto. Foi o que fez Maria Pia Pozzato numa tentativa no sentido inverso ao que propõem os Cultural Studies: analisou o público-modelo como "construção textual, um modelo de público que a televisão constrói e representa através dos próprios 'textos'” (Pozzato, 1995: 9). E o fez, o que é raro, analisando não-ficções. Diga-se, entre parêntesis, que estaremos aqui perante a um critério de qualidade: até que ponto um texto se adapta ao público que era pressuposto conquistar.

Centrar a análise sobre o texto tem ainda a vantagem de não perder a autonomia da avaliação para o mercado, a audimetria e as audiências, tomando o investigador o lugar do espectador: em frente do ecrã. Ele verá o mesmo que o espectador comum ou médio, mas não com os olhos dele, nem com os olhos ou as intenções e justificações do mercado e dos autores dos programas, por ser um técnico da análise independente. 
Estudos em Jornalismo e Mídia - Vol. 10 №2 - Julho a Dezembro de 2013

Em resumo, a avaliação da qualidade passa, a meu ver, pelas análises de conteúdo e textual mais ou menos detalhadas, se se lhes atribuir importância "como aspecto indispensável da avaliação" (Cardwell, 2007: 33). Estas metodologias permitem-nos atingir uma subjectividade muito objectiva da avaliação, quer seja quantitativa ou qualitativa.

A minha sétima nota de reflexão, e última, respeita à relação entre a avaliação da qualidade e a distinção, os marcadores de classe ou, de maneira geral, à antítese elitista-popular. Dado que em matéria de criação cultural, a distinção é fundamental, não é preciso ir muito longe para entender que ela explica muitas ou mesmo todas as dificuldades em torno da avaliação da qualidade na televisão. Eis uma dificuldade que decorre tanto do peso bruto da distinção a respeito dos conteúdos como do mesmo peso bruto sobre os próprios investigadores. Não é simples sair de si para analisar o tele-lixo e tudo o que gravita em seu redor. Há 25 séculos, Platão e Aristóteles escreveram sobre as recepções diferenciadas da criação cultural por parte de diferentes grupos sociais, os de cima e os de baixo. Ainda estamos aí? Onde estão os investigadores? Serão eles capazes de avaliar a partir dos elementos internos do texto e não dos elementos externos? (Jullier, 2002: 240) Tal parece-me não só possível como necessário, partindo da techné. Se houver critérios objectivos de avaliação e se tomar em conta o espectador pressuposto, o investigador estará mais próximo de uma avaliação objectiva que ignore o seu gosto. E a enorme aproximação contemporânea das escolhas e dos gostos dos de baixo e dos de cima, nomeadamente no que respeita aos conteúdos audiovisuais, simplifica a tarefa de encontrar mais facilmente critérios de avaliação interna para todos os géneros de conteúdos.

Em 1997, Casetti e di Chio, no seu excelente manual de instrumentos, métodos e práticas de investigação, no qual sistematizaram mais de trinta diferentes tipos, incluíram as análise de conteúdo e textual. Nessa altura, afirmavam que esta última era ainda "experimental" (Casetti e di Chio, 1999: 13). Passaram quinze anos. Os estudos de televisão equiparam-se de um vasto, e talvez incomparável entre as ciências sociais, conseguimento teórico e metodológico para a análise da qualidade, seja dos sistemas, canais, géneros e audiências, seja dos próprios programas. Falta-lhes tentar equipar-se de um paradigma da avaliação e de critérios partilhados, baseados em primeiro lugar na 
Estudos em Jornalismo e Mídia - Vol. 10 №2 - Julho a Dezembro de 2013

ISSNe 1984-6924

DOI: http://dx.doi.org//0.5007/I984-6924.20I3v10n2p282

análise dos programas. Depois dos períodos elitista e populista, chegámos a um ponto em que compete ao universo universitário dos estudos de televisão reclamar sem medo a sua autonomia para fazer a avaliação da qualidade ora dos constrangimentos dos capitais político, profissional, dos empresários e ainda do capital populista que atribui todo o poder de avaliação à audiência. ${ }^{5}$ Ao contrário de outros grupos, como os profissionais, o universo universitário tem a vantagem de teorizar, debater, desenvolver e poder aplicar critérios de avaliação com independência e considerar a qualidade como uma categoria neutra. É tempo de os investigadores ocuparem o seu lugar e fazerem valer a autoridade da sua preparação nos estudos de televisão para avaliar a qualidade, domínio que há demasiado tempo constitui um diálogo de surdos, um verdadeiro buraco negro, uma investigação sem paradigma, quase envergonhada. $\mathrm{O}$ debate sobre as metodologias da avaliação foi proposto há mais de vinte anos (Brunsdon, 1990: 69). Este colóquio poderá ser um bom início do fim do relativismo segundo o qual todas as avaliações se equivalem, contribuindo assim para a autonomia académica em matéria de avaliação e, portanto, para um conhecimento mais sistemático e concreto da qualidade da criação televisiva.

5 Escusado seria dizer que esta posição significa defender o conhecimento como próprio do universo académico, afirmação apenas necessária para evitar interpretações erradas (Joyrich, 2006: 135). 


\section{Referências Bibliográficas}

Aristote [Aristóteles]. 2000. Poética. Edición de Salvador Mas. Madrid: Ed. Biblioteca Nueva.

Austral, Universidad, Facultad de Comunicación. S.d. Presentación del Observatorio de la TV e Índice de Calidad Televisiva. In http://web.austral.edu.ar/comunicacion-observatorio-tv-quienes-somos.asp.

Bernard, David. 2008. La qualité des choses. In L'en-je lacanien, 2 (11): 173-180.

Borges, Gabriela. 2009. Diversidade da Programação do Serviço Público de Televisão: Pistas para a Avaliação do Contexto Português. In João Freire Filho, A TV em Transição: Tendências de Programação no Brasil e no Mundo, Porto Alegre, Editora Sulina: 223-246.

Borges, Gabriela, e Vítor Reia-Baptista, org. 2008. Discursos e Práticas de Qualidade na Televisão. Lisboa: Livros Horizonte.

Bourbon, Jérôme. 2009. La Télévision et le Peuple ou le Retour de la "Populace". In coord. Cécile Méadel, La Réception, Paris, CNRS Éditions: 69-88.

Brunsdon, Charlotte. 1990. Television, Aesthetics and Audiences. In ed. Patricia Mellancamp, Logics of Television, London, BFI.

Buonanno, Milly. 2004. La Qualità della Fiction. Dal Produto all'Ambiente Produttivo. In org. Milly Buonanno, Realtà Multiple. Concetti, Generi e Audience della Fiction TV, Nápoles, Liguori Editore.

Cardwell, Sarah. 2007. Is Quality Television Any Good? Generic distinctions, Evaluations and the Troubling Matter on Critical Judement. In eds. Janet McCabe e Kim Akass, Quality TV: Contemporary American Television and Beyond, Londres, I.B. Tauris: 19-34.

Casetti, Francesco, et Federico di Chio. 1999. Análisis de la Televisión. Instrumentos, métodos y prácticas de investigación. Barcelona: Paidós.

Caughie, John. 2000. Television Drama: Realism, Modernism and British Culture. Oxford: Oxford University Press.

D’Haenens, L. 1996. Réalisation, réception et recherche. Optimiser le dialogue communicateurtéléspectateur: un rôle pour le chercheur. In Réseaux, 77: 112-141.

Ellis, John. 1992. Visible Fictions. Londres: Routledge.

Esquenazi, Jean-Pierre. 2011. As Séries Televisivas. Lisboa: Texto \& Grafia.

Feuer, Jane. 2007. HBO and the Concept of Quality TV. In McCabe, Janet e Kim Akass, eds., Quality TV: Contemporary American Television and Beyond. London, I.B. Tauris: 145-157.

Fiske, John. 1987. Television Culture. Londres: Routledge.

Gitlin, Todd. 1997. The Anti-Political Populism of Cultural Studies. In Marjorie Ferguson and Peter Goulding, eds, Cultural Studies In Question, Londres, SAGE: 25-38.

Hammond, Michael, e Lucy Mazdon. 2005. The Contemporary Television Series. Edimburgo: Edinburgh University Press.

Ishikawa, Sakae, ed. 1996. Quality Assessment of Television. Luton: Luton University Press.

Jancovitch, Mark, e James Lyons, eds. 2003. Quality Popular Television. Londres: BFI.

Joyrich, Lynne. 2006. Ordering Law, Judging History: Deliberations on Court TV. In Wendy Hui Kyong Chun et Thomas Keenan, New Media, Old Media. A History and Theory Reader, Nova York et Oxon, Routledge: 133-153.

Jullier, Laurent. 2002. Qu'est-ce qu'un bom film? Paris: La Dispute.

Lasagni, M. Cristina, et Giuseppe Richeri. 1996. Television e Qualità. La ricerca internazionale. Il dibattito in Italia. Roma: RI-ERI.

Le Diberber, Alain. 1990. La qualité en télévision. In Études, 373 (1-2): 63-72.

Leverette, Marc, Brian L. Ott e Cara Louise Buckley. 2008. It's Not TV. Watching HBO In the Post Television Era. Nova York: Routledge.

McCabe, Janet e Kim Akass, eds. 2007. Quality TV: Contemporary American Television and Beyond. Londres: I.B. Tauris.

McGuigan, Jim. 1992. Cultural Populism. Londres: Routledge.

McGuigan, Jim. 2010. Cultural Analysis. Londres: SAGE.

McQuail, Denis. 2010. Mass Communication Theory. Londres: SAGE. 6th ed.

OBITEL. 2011. OBITEL 2011: Qualidade na Ficção Televisiva e Participação Transmidiática das Audiências. Rio de Janeiro: Globo Universidade.

Pozzato, M. Pia. 1995. Lo Spettatore senza Qualità. Competenze e Modelli di Pubblico Rappresentati in Televisione. Roma: RAI e Nuova ERI.

Pujadas, Eva. 2011. La Televisión de Calidad. Contenidos y Debates. Belígera, Castelló de la Plana, Barcelona e Valência: Universitat Autónoma de Barcelona - Servei de Publicacions, Publicacions de la universais Jaume I, Universitat Pompeu Fabra e Publicacions de la Univeristat de València. 
Raboy, Marc, ed. 1996. Public Broadcasting for the Twenty-first Century. Luton: John Libbey Media, University of Luton Press.

Rose, Gillian. 2008. Visual Methodologies. An Introduction to the Interpretation of Visual Materials. $2^{\text {nd }}$ ed. Londres: SAGE.

Rosengren, Karl Erik, with Mats Carlson and Yale Tågerud. 1996. Quality In Programming: Views from the North. In Sakai Ishikawa, ed., Quality Assessment of Television, Luton, Luton University Press: 3-48.

Sánchez Noriega, José Luis. 2002. Critica de la Seducción Mediática. Madrid: Ed. Tecnos. $2^{\mathrm{a}}$ ed.

Schrøeder, Kim. 1997. Calidad cultural: la persecucion de un fantasma?. In Daniel Dayan, org., En Busca del Publico, Barcelona, Editorial Gedisa: 107-125.

Silva, Vítor Manuel Aguiar e. 1991. Teoria da Literatura. Coimbra: Almedina. $8^{\mathrm{a}}$ ed.

Swanson, Dorothy Collins. 2000. The Story of Viewers for Quality Television. From Grassroots to Prime Time. Syracuse, NY: Syracuse University Press.

Thompson, Robert J. 2007. Preface. In eds. Janet McCabe e Kim Akass, Quality TV: Contemporary American Television and Beyond, Londres, I.B. Tauris: xvii-xx.

Torres, Eduardo Cintra. 2000. As elites e os “programas de qualidade”. In Público, 01.05.2000.

Torres, Eduardo Cintra Torres. 2004. A Ética e a Crítica Jornalística. In Revista de Comunicação e Marketing, Lisboa, ISCEM, nº4: 9-18.

Torres, Eduardo Cintra. 2011. A Crítica Jornalística na Era do Receptor Empoderado. In Contemporânea, Revista de Comunicação e Cultura, Vol. 9, N1 (2011), Universidade Federal da Bahia, 5-21. Link: http://www.portalseer.ufba.br/index.php/contemporaneaposcom/article/view/4921/3689

Este artigo e todo o conteúdo da Estudos em Jornalismo e Mídia

estão disponíveis em http://www.periodicos.ufsc.br/index.php/jornalismo/index

Estudos em Jornalismo e Mídia está sob a Licença Creative Commons 